\title{
ORIGINAL ARTICLE GENDER-BASED DIFFERENCES IN CLINICAL PROFILE AND OUTCOME OF PRIMARY PERCUTANEOUS CORONARY INTERVENTION IN PATIENTS WITH ST-SEGMENT ELEVATION MYOCARDIAL INFARCTION
}

\author{
Syed Muhammad Afaque', Atif Sher Muhammad', Mukesh Kumar'1, Kanwal Fatima \\ Aamir', Aftab Ahmed', Najia Aslam Soomro², Musa Karim¹, Tariq Ashraf ${ }^{3}$ \\ ${ }^{1}$ National Institute of Cardiovascular Diseases, Karachi, Pakistan, ${ }^{2}$ Liaquat National Hospital, Karachi, Pakistan, ${ }^{3}$ Karachi Institute of \\ Heart Diseases (KIHD), Karachi, Pakistan
}

Objectives: A conflict of evidence exists regarding the gender-based differences in outcomes after primary percutaneous coronary intervention (PCI), therefore, aim of this study was to compare the clinical characteristics, angiographic findings, and outcome of primary PCI for men and women.

Methodology: Data for this study was extracted from a prospectively managed primary PCI database of the National Institute of Cardiovascular Diseases (NICVD), Karachi, Pakistan. We included consecutive patients of either gender with STEMI undergone primary PCI. Data on clinical characteristics, angiographic finding, and post procedure outcomes for female were compared with male group and also with a propensity matched male cohort.

Results: A total of 2400 patients were included with 421(17.5\%) women. The mean age for the men and women were $54.44 \pm 11.16$ and $57.17 \pm 11.01$ years respectively; $<<0.001$. Women had significantly high prevalence of hypertension $(61.0 \%$ vs. $39.1 \% ; \mathrm{p}<0.001)$, diabetes $(37.1 \%$ vs. $23.9 \%$; $\mathrm{p}<0.001)$, and obesity ( $18.5 \%$ vs. $13.5 \%$; $=0.008)$. The median symptom onset to hospital arrival time was 216 [366-124] minutes vs. 180 [310-112] minutes; $\mathrm{p}=0.001$ for women and men. In-hospital mortality rate was $3.8 \%$ vs. $2.5 \%$; $=0.147$ for female and unmatched male cohort, while it was $3.6 \%$ vs. $3.8 \%$; $\mathrm{p}=0.855$ for female and propensity matched male cohort. Conclusion: Gender-based differences persist in clinical profile of the patients with STEMI. Women are likely to be older in age with more diabetes, hypertension, and obesity. Genderbased difference in outcome of primary PCI is appears to be driven by differences in clinical profile as adjusted outcome is not different for men and women.

Keywords: cardiovascular diseases, acute myocardial infarction, ST-segment elevation myocardial infarction, primary percutaneous coronary intervention, gender-difference, female, outcome

Citation: Afaque SM, Muhammad AS, Kumar M, Aamir KF, Ahmed A, Soomro NA, Karim M, Ashraf T. Genderbased Differences in Clinical Profile and Outcome of Primary Percutaneous Coronary Intervention in Patients with ST-Segment Elevation Myocardial Infarction. Pak Heart J. 2021;54(03):254-260. DOI: https://doi.org/10.47144/phj.v54i3.2167

\section{INTRODUCTION}

Cardiovascular diseases (CVD) remains a leading cause of death among both male and female, but a significantly different epidemiological landscape has been observed for men and women along with evidence of different clinical expression of atherosclerosis and pathophysiology of disease. ${ }^{1}$ The incidence rate of CVD, especial during reproductive years, is significantly lower for women when compared to men population with an almost 10 years of gape in average presentation age. It can be partly attributed to the cardioprotective mechanism of the main female sex circulating hormone, the estrogen., ${ }^{2,3}$ Where there is comparatively lower risk of development of diseases, but the clinical evidence suggest that the female gender as an independent prognostic indicator after acute coronary event. Various studies have found female gender to be associated with a significant increased risk of shortand long-term mortality after acute coronary event. ${ }^{4-13}$ Nonetheless, there exist a conflict of evidence as ample literature also available suggesting either no gender differences in outcomes or attributing differences in outcomes with differences in baseline characteristics or increased burden of comorbidities in women due to relatively older age at presentation. ${ }^{14,15}$

Studies reporting gender disparities in outcomes postulated various determinants of higher rate of adverse events in women, some studies argued that the atypical clinical presentation is more common among women also pre-hospital delay is more common for females as compared to their male counterpart 
resulting in delay in reperfusion therapy. ${ }^{7,9,10,16-18}$ It has been also observed that women are less likely to receive aggressive management and guideline directed medical therapy (GDMT). ${ }^{7-9,16}$

Primary percutaneous coronary intervention (PCI), when performed within 12 hours of window period, is the treatment of choice for the restoration of myocardium in patients with ST-segment elevation myocardial infarction (STEMI). ${ }^{19,}{ }^{20}$ However, a very limited data are available regarding gender-based difference in angiographic profile and outcomes of STEMI patients in Pakistani population. Our center is the largest cardiac care center of the country, therefore, in this study we aimed to compare the clinical characteristics, angiographic findings, and outcome of primary PCI for men and women presented with STEMI.

\section{METHODOLOGY}

After the approval of the institutional ethical review committee, data for this study was extracted from the prospectively managed primary PCI database of the National Institute of Cardiovascular Diseases (NICVD), Karachi, Pakistan. We included data of consecutive patients, both male and female, presented with STEMI undergone primary PCI at NICVD, Karachi, Pakistan during July 2017 and June 2018. Patients with missing information regarding the study variables such as clinical presentation, angiographic finding, and post-procedure outcomes were excluded from the analysis.

Extracted data were consisted of clinical characteristics, such as age, gender, risk profile, and timing of hospital arrival and procedure, angiographic characteristics, such as diseases burden, infarct related artery (culprit artery), and lesion characteristics and complexity, procedural details and post procedure outcomes and complication. A detailed methodology of data collected is defined elsewhere. ${ }^{21}$

Data analysis were performed with the help of IBM SPSS version 21. Data were stratified by gender and comparative analysis between men and women for clinical characteristics, angiographic characteristics, procedural details, and post procedure outcomes were performed by applying independent sample t-test for continuous variables, such as age, body mass index (BMI), symptom onset to hospital arrival time, hospital arrival to procedure time, total ischemic time, lesion length, fluoroscopic time, and contrast volume, and mean \pm standard deviation (SD) and median [interquartile range (IQR)] were computed. Categorical variables were compared by applying the Chi-square test and frequencies and percentages were calculated. The criteria for statistical significance of the difference between men and women was $\mathrm{p} \leq 0.05$ throughout the analysis. Considering the statistical implication of female to male ratio of 1:4.7 in our dataset, a propensity matched cohort in 1:1 ratio of female and male was formed. Propensity matching was performed using "MatchIt" package on $\mathrm{R}$ software version 3.6.1 and profile variables for matching were age, BMI, co-morbid conditions such as hypertension, diabetes, smoking, prior history of myocardial infarction, duration to hospital arrival after symptom onset, duration to procedure after hospital arrival, and cardiogenic shock at presentation.

\section{RESULTS}

A total of 2400 STEMI patients undergone primary PCI were included in this analysis, $421(17.5 \%)$ were female and remaining $1,979(82.5 \%)$ were male patients. The male STEMI patient cohort was observed to be younger than their female counter part with mean age of $54.44( \pm 11.16)$ years vs. $57.17( \pm$ 11.01) years; $\mathrm{p}<0.001$, respectively. Similarly, the premature MI ( $\leq 40$ years) was more commonly observed for the male cohort, $10.7 \%$ (211) vs. $5.2 \%$ (22); $\mathrm{p}<0.001$. Relatively more complex cardiovascular disease risk profile was observed for the female cohort with more hypertension $(61.0 \%$ vs. $39.1 \%$; p<0.001), more diabetes $(37.1 \%$ vs. $23.9 \%$; $\mathrm{p}<0.001)$, and more obesity $(18.5 \%$ vs. $13.5 \%$; $\mathrm{p}=0.008$ ), while smoking was more common for the male cohort, $30.7 \%$ vs. $1.9 \%$; $\mathrm{p}<0.001$, respectively. The demographic and clinical characteristics of the male and female cohorts are presented in Table 1.

A delay of more than half an hour was observed for female patients, as compared to their male counterpart, in symptom onset to hospital arrival, 216 [366-124] minutes vs. 180 [310-112] minutes; $\mathrm{p}=0.001$, and for $42.8 \%$ of the female (vs. $35.8 \%$ for male) patients the symptom onset to hospital arrival time was more than four hours. Similarly, around 13 minutes of delay was observed for females in hospital arrival to the procedure time, 77 [107-55] minutes vs. 64 [95-42] minutes; $\mathrm{p}<0.001$, and hospital arrival to the procedure time exceeds a standard cutoff of 90 minutes for $38.2 \%$ of the female (vs. $27.5 \%$ for male) patients. Presentation and procedure timing are presented in Table 1.

The angiographic characteristics and in-hospital outcomes of the male and female cohorts are presented in Table 2. Both, male and female, cohorts are found to be alike in angiographic profile such as preprocedure Thrombolysis in Myocardial Infarction (TIMI) flow grade $(\mathrm{p}=0.635)$, number of diseased 
vessels $(\mathrm{p}=0.359)$, and infarct related artery $(\mathrm{p}=0.232)$. The post-procedure TIMI flow grade III was not achieved in relatively higher proportion of female patients as compared to male patients, $5.5 \%$ vs. $3.2 \%$; $\mathrm{p}=0.026$, respectively. In-hospital mortality rate was also relatively higher for the female cohort, 3.8\% (vs. $2.5 \%$ for male), however, no statistically significant differences were observed in in-hospital outcomes of both male and female cohorts.
The angiographic profile and in-hospital outcomes for the females were found to be not statistically significant from that of a propensity matched male cohort. Conversely in-hospital mortality rate was found slightly higher in male cohort as compared to female with mortality rates of $3.8 \%$ vs. $3.6 \%$; $=0.855$ for male and female respectively. The angiographic profile and in-hospital outcomes for female and male matched cohorts are presented in Table 3.

Table 1: Demographic and clinical characteristics stratified by gender

\begin{tabular}{|c|c|c|c|c|}
\hline \multirow{2}{*}{ Characteristics } & \multirow{2}{*}{ Total } & \multicolumn{2}{|c|}{ Gender } & \multirow{2}{*}{ P-value } \\
\hline & & Male & Female & \\
\hline Total (N) & 2400 & 1979 & 421 & - \\
\hline Age (mean \pm SD years) & $54.92 \pm 11.18$ & $54.44 \pm 11.16$ & $57.17 \pm 11.01$ & $<0.001$ \\
\hline$\leq 40$ years & $233(9.7 \%)$ & $211(10.7 \%)$ & $22(5.2 \%)$ & \multirow{3}{*}{$<0.001$} \\
\hline 41 to 65 years & $1745(72.7 \%)$ & $1445(73 \%)$ & $300(71.3 \%)$ & \\
\hline$>65$ years & $422(17.6 \%)$ & $323(16.3 \%)$ & $99(23.5 \%)$ & \\
\hline BMI $\left(\mathrm{kg} / \mathrm{m}^{2}\right)$ & $26.09 \pm 4.46$ & $26.11 \pm 4.37$ & $25.99 \pm 4.85$ & 0.665 \\
\hline$\leq 18.5 \mathrm{~kg} / \mathrm{m}^{2}$ & $51(2.1 \%)$ & $32(1.6 \%)$ & $19(4.5 \%)$ & \multirow{4}{*}{$<0.001$} \\
\hline 18.5 to $25 \mathrm{~kg} / \mathrm{m}^{2}$ & $982(40.9 \%)$ & $815(41.2 \%)$ & $167(39.7 \%)$ & \\
\hline 25 to $30 \mathrm{~kg} / \mathrm{m}^{2}$ & $1021(42.5 \%)$ & $864(43.7 \%)$ & $157(37.3 \%)$ & \\
\hline$>30 \mathrm{~kg} / \mathrm{m}^{2}$ & $346(14.4 \%)$ & $268(13.5 \%)$ & $78(18.5 \%)$ & \\
\hline \multicolumn{5}{|l|}{ Risk factors } \\
\hline Hypertension & $1031(43 \%)$ & $774(39.1 \%)$ & $257(61 \%)$ & $<0.001$ \\
\hline Diabetes & $629(26.2 \%)$ & $473(23.9 \%)$ & $156(37.1 \%)$ & $<0.001$ \\
\hline Smoking & $615(25.6 \%)$ & $607(30.7 \%)$ & $8(1.9 \%)$ & $<0.001$ \\
\hline Family history of CAD & $82(3.4 \%)$ & $70(3.5 \%)$ & $12(2.9 \%)$ & 0.481 \\
\hline Past history of myocardial infarction & $153(6.4 \%)$ & $142(7.2 \%)$ & $11(2.6 \%)$ & $<0.001$ \\
\hline \multicolumn{5}{|c|}{ Symptom onset to hospital arrival time (minutes) } \\
\hline Median [IQR] & 185 [323.5-115] & 180 [310-112] & 216 [366-124] & 0.001 \\
\hline$\leq 120$ minutes & $682(28.4 \%)$ & $579(29.3 \%)$ & $103(24.5 \%)$ & \multirow{3}{*}{0.021} \\
\hline 121 to 240 minutes & $829(34.5 \%)$ & $691(34.9 \%)$ & $138(32.8 \%)$ & \\
\hline$>240$ minutes & $889(37 \%)$ & $709(35.8 \%)$ & $180(42.8 \%)$ & \\
\hline \multicolumn{5}{|l|}{ Hospital arrival to procedure time (minutes) } \\
\hline Median [IQR] & $65[97-43]$ & $64[95-42]$ & 77 [107-55] & $<0.001$ \\
\hline$\leq 90$ minutes & $1695(70.6 \%)$ & $1435(72.5 \%)$ & $260(61.8 \%)$ & \multirow{2}{*}{0.021} \\
\hline$>90$ minutes & $705(29.4 \%)$ & $544(27.5 \%)$ & $161(38.2 \%)$ & \\
\hline \multicolumn{5}{|l|}{ Cardiogenic shock (CS) } \\
\hline No & $2327(97 \%)$ & $1922(97.1 \%)$ & $405(96.2 \%)$ & \multirow{2}{*}{0.318} \\
\hline Yes & $73(3 \%)$ & $57(2.9 \%)$ & $16(3.8 \%)$ & \\
\hline Pre-procedure serum creatinine $(\mathrm{mg} / \mathrm{dL})$ & $0.87 \pm 0.76$ & $0.86 \pm 0.65$ & $0.87 \pm 1.13$ & 0.897 \\
\hline Hemoglobin $(g / d L)$ & $11.06 \pm 5.35$ & $11.26 \pm 5.48$ & $10.11 \pm 4.54$ & $<0.001$ \\
\hline
\end{tabular}

$C A D=$ coronary artery diseases, $S D=$ standard deviation, $B M I=$ body mass index, IQR = interquartile range

Table 2: Angiographic findings and in-hospital outcomes of primary PCI stratified by gender

\begin{tabular}{|c|c|c|c|c|}
\hline \multirow{2}{*}{ Characteristics } & \multirow{2}{*}{ Total } & \multicolumn{2}{|c|}{ Gender } & \multirow{2}{*}{ P-value } \\
\hline & & Male & Female & \\
\hline Total (N) & 2400 & 1979 & 421 & - \\
\hline \multicolumn{5}{|c|}{ Pre-procedure Thrombolysis in Myocardial Infarction (TIMI) flow grade } \\
\hline TIMI 0 & $1391(58 \%)$ & $1141(57.7 \%)$ & $250(59.4 \%)$ & \multirow{3}{*}{0.635} \\
\hline TIMI I & $231(9.6 \%)$ & $192(9.7 \%)$ & $39(9.3 \%)$ & \\
\hline TIMI II & $465(19.4 \%)$ & $392(19.8 \%)$ & $73(17.3 \%)$ & \\
\hline
\end{tabular}


TIMI III

\begin{tabular}{|c|c|c|}
\hline $313(13 \%)$ & $254(12.8 \%)$ & $59(14 \%)$ \\
\hline $16(0.7 \%)$ & $12(0.6 \%)$ & $4(1 \%)$ \\
\hline $800(33.3 \%)$ & $667(33.7 \%)$ & $133(31.6 \%)$ \\
\hline $689(28.7 \%)$ & $556(28.1 \%)$ & $133(31.6 \%)$ \\
\hline $534(22.3 \%)$ & $437(22.1 \%)$ & $97(23 \%)$ \\
\hline $361(15 \%)$ & $307(15.5 \%)$ & $54(12.8 \%)$ \\
\hline
\end{tabular}

Number of vessels involved

None

Single vessel disease (SVD)

Two vessels disease (2VD)

Three vessels disease (3VD)

Data not available

$361(15 \%)$

$307(15.5 \%)$

$54(12.8 \%)$

Infarct related artery

Left anterior descending artery (LAD)

Right coronary artery (RCA)

Left circumflex artery (LCX)

Pulmonary descending artery (PDA)

Ramus

Left main artery (LM)

\begin{tabular}{|c|c|c|}
\hline $1304(54.3 \%)$ & $1093(55.2 \%)$ & $211(50.1 \%)$ \\
\hline $795(33.1 \%)$ & $638(32.2 \%)$ & $157(37.3 \%)$ \\
\hline $258(10.8 \%)$ & $210(10.6 \%)$ & $48(11.4 \%)$ \\
\hline $19(0.8 \%)$ & $18(0.9 \%)$ & $1(0.2 \%)$ \\
\hline $9(0.4 \%)$ & $7(0.4 \%)$ & $2(0.5 \%)$ \\
\hline $15(0.6 \%)$ & $13(0.7 \%)$ & $2(0.5 \%)$ \\
\hline
\end{tabular}

0.232

Lesion Complexity

Non-High/Non-C Lesion

High/C Lesion

Bifurcation lesion

Lesion length (mm)

Fluoroscopy time (minutes)

Contrast volume (ml)

Stent type

POBA

Drug Eluting Stent (DES)

Bare Metal Stent (BMS)

\begin{tabular}{|c|c|c|}
\hline $1344(56 \%)$ & $1101(55.6 \%)$ & $243(57.7 \%)$ \\
\hline $1056(44 \%)$ & $878(44.4 \%)$ & $178(42.3 \%)$ \\
\hline $632(26.3 \%)$ & $524(26.5 \%)$ & $108(25.7 \%)$ \\
\hline $18.92 \pm 8.18$ & $18.98 \pm 8.2$ & $18.66 \pm 8.06$ \\
\hline $14.07 \pm 8$ & $14.12 \pm 8.16$ & $13.85 \pm 7.2$ \\
\hline $138.45 \pm 46.64$ & $138.42 \pm 46.41$ & $138.57 \pm 47.79$ \\
\hline $160(6.7 \%)$ & $131(6.6 \%)$ & $29(6.9 \%)$ \\
\hline $1239(51.6 \%)$ & $1041(52.6 \%)$ & $198(47 \%)$ \\
\hline $1001(41.7 \%)$ & $807(40.8 \%)$ & $194(46.1 \%)$ \\
\hline
\end{tabular}

0.434

0.727

0.462

0.53

0.953

Post-procedure Thrombolysis in Myocardial Infarction (TIMI) flow grade

\begin{tabular}{|l|c|c|c|}
\hline TIMI 0 & $14(0.6 \%)$ & $13(0.7 \%)$ & $1(0.2 \%)$ \\
TIMI I & $16(0.7 \%)$ & $12(0.6 \%)$ & $4(1 \%)$ \\
\hline TIMI II & $57(2.4 \%)$ & $39(2 \%)$ & $18(4.3 \%)$ \\
\hline TIMI III & $2313(96.4 \%)$ & $1915(96.8 \%)$ & $398(94.5 \%)$
\end{tabular}

0.107

Post-procedure in-hospital outcomes

Mortality

Re-infarction

Cardiogenic shock (CS)

Heart failure (HF)

Cerebrovascular accident

Bleeding

Dialysis

Transfusion

$2313(96.4 \%)$

$1915(96.8 \%)$

$398(94.5 \%)$

0.022

$P C I=$ percutaneous coronary intervention, $P O B A=$ plain old balloon angioplasty

Table 3: Angiographic findings and in-hospital outcomes of primary PCI stratified by gender for matched cohort

\begin{tabular}{|c|c|c|c|}
\hline \multirow{2}{*}{ Characteristics } & \multicolumn{2}{|c|}{ Gender } & \multirow{2}{*}{ p-value } \\
\hline & Male & Female & \\
\hline Total (N) & 421 & 421 & - \\
\hline \multicolumn{4}{|c|}{ Pre-procedure Thrombolysis in Myocardial Infarction (TIMI) flow grade } \\
\hline TIMI 0 & $244(58 \%)$ & $250(59.4 \%)$ & \multirow{4}{*}{0.141} \\
\hline TIMI I & $42(10 \%)$ & $39(9.3 \%)$ & \\
\hline TIMI II & $93(22.1 \%)$ & $73(17.3 \%)$ & \\
\hline TIMI III & $42(10 \%)$ & $59(14 \%)$ & \\
\hline \multicolumn{4}{|c|}{ Number of vessels involved } \\
\hline None & $1(0.2 \%)$ & $4(1 \%)$ & 0.344 \\
\hline
\end{tabular}




\begin{tabular}{|c|c|c|c|}
\hline Single vessel disease (SVD) & $114(27.1 \%)$ & $133(31.6 \%)$ & \\
\hline Two vessels disease (2VD) & $137(32.5 \%)$ & $133(31.6 \%)$ & \\
\hline Three vessels disease (3VD) & $105(24.9 \%)$ & $97(23 \%)$ & \\
\hline Data not available & $64(15.2 \%)$ & $54(12.8 \%)$ & \\
\hline \multicolumn{4}{|l|}{ Infarct related artery } \\
\hline Left anterior descending artery (LAD) & $227(53.9 \%)$ & $211(50.1 \%)$ & \multirow{6}{*}{0.274} \\
\hline Right coronary artery (RCA) & $141(33.5 \%)$ & $157(37.3 \%)$ & \\
\hline Left circumflex artery (LCX) & $42(10 \%)$ & $48(11.4 \%)$ & \\
\hline Pulmonary descending artery (PDA) & $7(1.7 \%)$ & $1(0.2 \%)$ & \\
\hline Ramus & $2(0.5 \%)$ & $2(0.5 \%)$ & \\
\hline Left main artery (LM) & $2(0.5 \%)$ & $2(0.5 \%)$ & \\
\hline \multicolumn{4}{|l|}{ Lesion Complexity } \\
\hline Non-High/Non-C Lesion & $235(55.8 \%)$ & $243(57.7 \%)$ & \multirow{2}{*}{0.578} \\
\hline High/C Lesion & $186(44.2 \%)$ & $178(42.3 \%)$ & \\
\hline Bifurcation lesion & $111(26.4 \%)$ & $108(25.7 \%)$ & 0.814 \\
\hline Lesion length $(\mathrm{mm})$ & $19.56 \pm 8.72$ & $18.66 \pm 8.06$ & 0.118 \\
\hline Fluoroscopy time (minutes) & $14.97 \pm 9.17$ & $13.85 \pm 7.2$ & 0.05 \\
\hline Contrast volume (ml) & $140.96 \pm 47.8$ & $138.57 \pm 47.79$ & 0.467 \\
\hline \multicolumn{4}{|l|}{ Stent type } \\
\hline POBA & $23(5.5 \%)$ & $29(6.9 \%)$ & \multirow{3}{*}{0.337} \\
\hline Drug Eluting Stent (DES) & $218(51.8 \%)$ & $198(47 \%)$ & \\
\hline Bare Metal Stent (BMS) & $180(42.8 \%)$ & $194(46.1 \%)$ & \\
\hline \multicolumn{4}{|c|}{ Post-procedure Thrombolysis in Myocardial Infarction (TIMI) flow grade } \\
\hline TIMI 0 & $2(0.5 \%)$ & $1(0.2 \%)$ & \multirow{4}{*}{0.667} \\
\hline TIMI I & $4(1 \%)$ & $4(1 \%)$ & \\
\hline TIMI II & $12(2.9 \%)$ & $18(4.3 \%)$ & \\
\hline TIMI III & $403(95.7 \%)$ & $398(94.5 \%)$ & \\
\hline \multicolumn{4}{|l|}{ Post-procedure in-hospital outcomes } \\
\hline Mortality & $15(3.6 \%)$ & $16(3.8 \%)$ & 0.855 \\
\hline Re-infarction & $2(0.5 \%)$ & $0(0 \%)$ & 0.157 \\
\hline Cardiogenic shock (CS) & $7(1.7 \%)$ & $4(1 \%)$ & 0.363 \\
\hline Heart failure $(\mathrm{HF})$ & $6(1.4 \%)$ & $3(0.7 \%)$ & 0.315 \\
\hline Cerebrovascular accident & $2(0.5 \%)$ & $1(0.2 \%)$ & 0.563 \\
\hline Bleeding & $3(0.7 \%)$ & $2(0.5 \%)$ & 0.654 \\
\hline Dialysis & $1(0.2 \%)$ & $2(0.5 \%)$ & 0.563 \\
\hline Transfusion & $1(0.2 \%)$ & $1(0.2 \%)$ & $>0.999$ \\
\hline
\end{tabular}

$P C I=$ percutaneous coronary intervention, $P O B A=$ plain old balloon angioplasty

\section{DISCUSSION}

To the best of our knowledge this is the largest study conducted in Pakistani population assessing genderbased differences in angiographic findings and outcomes of primary PCI in patients with STEMI. We observed that female patients comprises of less than $1 / 5$ th of clinical burden of STEMI patients. Premature MI ( $\leq 40$ years) is less common among female and female patients are relatively older than male counterpart due to which women are more likely to be diabetic, hypertensive, and obese as compared to men, but less likely to be smokers. These observations regarding female patients were concord with the past studies, with average age difference between female and male patients is reported to be ranging from 5 to 10 years. . $^{4,9,12,13,15,22,23}$
In this study we have also observed that the STEMI management timeline for women is different as compared to men, female patients had significant higher time lapse between onset of symptoms to hospital arrival as well as hospital arrival to the procedure, resulting in aggregate delay in timely restoration of myocardium. Similar observations were made by some of the previous studies. ${ }^{4,}$ 9, 23 Prehospital delay in patients with acute myocardial infarction (AMI) is one of important predictors of adverse outcomes and complications, it has been reported that with every 30 minutes of delay in reperfusion after AMI, risk of 1-year mortality and complication increases by 7.5 times. ${ }^{24}$ Bugiardini $R$ et al. ${ }^{25}$ conducted a comparative study of male and female 6022 patients with STEMI registered from 41 hospitals participated in the International Survey of 
Acute Coronary Syndromes in Transitional Countries (ISACS-TC) registry and observed that female patients are more exposed to prolonged untreated ischemia, further, higher rate of mortality among women found to be associated with pre-hospital delay even after adjusting for the baseline characteristics.

In this study we observed that the angiographic findings, such as number of diseases vessels, infarcted related artery, and pre-procedure TIMI flow grade, in female patients were not different from that of male. But post-procedure outcomes and complications such as no reflow and in-hospital mortality rate were relatively higher among female patients. Studies of various nature have also reported the same observation of relatively or significantly higher rate of adverse outcomes among women. ${ }^{4,5,8,9,12,13,15, ~ 22, ~} 25$ However, differences in outcomes was suspected to be driven by the fact that female patients had more high risk clinical profile as compared to male patients, which included older age, more diabetic, more hypertensive, more obese, and prolonged exposure to the untreated ischemia. Therefore, female patients were compared to the propensity matched cohort of male patients which showed that the apparent difference by gender in in-hospital mortality rate diminished. A similar observation of no difference in outcome of primary PCI in male and female patients after adjusting for the baseline risk profile was evident in various studies from the past. ${ }^{12,15,22,25}$

Even though, to the best of our knowledge this is the largest study of its kind based on a single center based registry maintained by the largest cardiac care center of the Pakistan, our studies has limitations, data regarding only post-procedure in-hospital outcomes were available, therefore, no inferences can be made regarding role of female gender in short- and longterm outcomes after primary PCI. Even though it was based on prospectively maintained registry, but exclusion of cases with missing information on study variables may introduce a selection bias.

\section{CONCLUSION}

In conclusion, female patients comprises of less than onefifth of the total clinical burden of STEMI. Women with STEMI are more likely to be older, hypertensive, diabetic, and obese. The angiographic findings are likely to be similar for both genders but the differences in outcomes after primary PCI may persist. The differences in outcomes may likely to be driven by the differences in clinical profile, once adjusted for the clinical profile the difference in outcomes diminishes.

\section{AUTHORS' CONTRIBUTION}

SMA, TA, and MK: Concept and design, data acquisition, interpretation, drafting, final approval, and agree to be accountable for all aspects of the work. ASM, MK, KFA, AA, and NAS: Data acquisition, interpretation, drafting, final approval and agree to be accountable for all aspects of the work.

Conflict of interest: Authors declared no conflict of interest.

\section{REFERENCES}

1. Wake R, Yoshiyama M. Gender differences in ischemic heart disease. Recent Pat Cardiovasc Drug Discov. 2009;4(3):234-40.

2. Iorga A, Cunningham CM, Moazeni S, Ruffenach G, Umar S, Eghbali M. The protective role of estrogen and estrogen receptors in cardiovascular disease and the controversial use of estrogen therapy. Biol Sex Differ. 2017;8(1):1-16.

3. Menazza S, Murphy E. The expanding complexity of estrogen receptor signaling in the cardiovascular system. Circ Res. 2016;118(6):994-1007.

4. Venetsanos D, Lawesson SS, Alfredsson J, Janzon M, Cequier A, Chettibi M, et al. Association between gender and short-term outcome in patients with ST elevation myocardial infraction participating in the international, prospective, randomised Administration of Ticagrelor in the catheterisation Laboratory or in the Ambulance for New ST elevation myocardial Infarction to open the Coronary artery (ATLANTIC) trial: a prespecified analysis. BMJ Open. 2017;7(9):e015241.

5. Zachura M, Wilczek K, Kurzawski J, Gierlotka M, Gąsior M, Sadowski M. Gender-related differences in men and women with ST-segment elevation myocardial infarction and incomplete infarct-related artery flow restoration: a multicenter national registry. Postepy Kardiol Interwencyjnej. 2018;14(4):356.

6. Juhan N, Zubairi YZ, Zuhdi A, Khalid ZM, Ahmad WAW. Gender differences in mortality among ST elevation myocardial infarction patients in Malaysia from 2006 to 2013. Ann Saudi Med. 2018;38(1):1-7.

7. Khan E, Brieger D, Amerena J, Atherton JJ, Chew DP, Farshid A, et al. Differences in management and outcomes for men and women with ST-elevation myocardial infarction. Med J Aust. 2018;209(3):118-23.

8. Shah P, Patel K, Vasudev R, Patel H, Thakkar S, Adalja D, et al. Gender differences in the revascularization rates and in-hospital outcomes in hospitalizations with ST segment elevation myocardial infarction. Ir J Med Sci. 2019:1-12.

9. Mahajan K, Negi PC, Merwaha R, Mahajan N, Chauhan V, Asotra $\mathrm{S}$. Gender differences in the management of acute coronary syndrome patients: One year results from HPIAR (HP-India ACS Registry). Int J Cardiol. 2017;248:1-6.

10. Rao U, Buchanan GL, Hoye A. Outcomes After Percutaneous Coronary Intervention in Women: Are There Differences When Compared with Men? Interv Cardiol. 2019;14(2):70.

11. Guo Y, Yin F, Fan C, Wang Z. Gender difference in clinical outcomes of the patients with coronary artery disease after percutaneous coronary intervention: a systematic review and meta-analysis. Medicine. 2018;97(30).

12. Zheng X, Dreyer RP, Hu S, Spatz ES, Masoudi FA, Spertus JA, et al. Age-specific gender differences in early mortality following ST-segment elevation myocardial infarction in China. Heart. 2015;101(5):349-55.

13. Liu Y, Wang LF, Yang XF, Ge YG, Wang HG, Xu L, et al. Gender differences in efficacy of primary percutaneous coronary intervention in patients with ST-elevation myocardial infarction. Chin Med J (Engl). 2008;121(23):2374-8.

14. Hao Y, Liu J, Liu J, Yang N, Smith Jr SC, Huo Y, et al. Sex Differences in In-Hospital Management and Outcomes of Patients 
With Acute Coronary Syndrome. Circulation. 2019;139(15):1776-85.

15. Zhang Q, Qiu JP, Zhang RY, Li YG, He B, Jin HG, et al. Absence of gender disparity in short-term clinical outcomes in patients with acute ST-segment elevation myocardial infarction undergoing sirolimus-eluting stent based primary coronary intervention: a report from Shanghai Acute Coronary Event (SACE) Registry. Chin Med J (Engl). 2010;123(7):782-8.

16. Lewis WR, Ellrodt AG, Peterson E, Hernandez AF, LaBresh KA, Cannon CP, et al. Trends in the use of evidence-based treatments for coronary artery disease among women and the elderly: findings from the get with the guidelines quality-improvement program. Circ Cardiovasc Qual Outcomes. 2009;2(6):633-41.

17. Lawesson SS, Isaksson RM, Ericsson M, Ängerud K, Thylén I. Gender disparities in first medical contact and delay in STelevation myocardial infarction: a prospective multicentre Swedish survey study. BMJ Open. 2018;8(5):e020211.

18. McNair PW, Bilchick KC, Keeley EC. Very late presentation in ST elevation myocardial infarction: predictors and long-term mortality. Int J Cardiol Heart Vasc. 2019;22:156-9.

19. Levine GN, Bates ER, Blankenship JC, Bailey SR, Bittl JA, Cercek B, et al. 2015 ACC/AHA/SCAI focused update on primary percutaneous coronary intervention for patients with ST-elevation myocardial infarction: an update of the 2011 ACCF/AHA/SCAI guideline for percutaneous coronary intervention and the 2013 ACCF/AHA guideline for the management of ST-elevation myocardial infarction. J Am Coll Cardiol. 2016;67(10):1235-50.
20. Ibanez B, James S, Agewall S, Antunes MJ, Bucciarelli-Ducci C, Bueno H, et al. 2017 ESC Guidelines for the management of acute myocardial infarction in patients presenting with ST-segment elevation: The Task Force for the management of acute myocardial infarction in patients presenting with ST-segment elevation of the European Society of Cardiology (ESC). Eur Heart J. 2018;39(2):119-77.

21. Ashraf T, Khan MN, Afaque SM, Aamir KF, Kumar M, Saghir T, et al. Clinical and procedural predictors and short-term survival of the patients with no reflow phenomenon after primary percutaneous coronary intervention. Int J Cardiol. 2019;294:2731.

22. Ghaffari S, Pourafkari L, Tajlil A, Bahmani-Oskoui R, Nader ND. Is female gender associated with worse outcome after ST elevation myocardial infarction? Indian Heart J. 2017;69:S28-S33.

23. Alshahrani H, McConkey R, Wilson J, Youssef M, Fitzsimons D. Female gender doubles pre-hospital delay times for patients experiencing ST segment elevation myocardial infarction in Saudi Arabia. Eur J Cardiovasc Nurs. 2014;13(5):399-407.

24. De Luca G, Suryapranata H, Ottervanger JP, Antman EM. Time delay to treatment and mortality in primary angioplasty for acute myocardial infarction: every minute of delay counts. Circulation. 2004;109(10):1223-5.

25. Bugiardini R, Ricci B, Cenko E, Vasiljevic Z, Kedev S, Davidovic $\mathrm{G}$, et al. Delayed care and mortality among women and men with myocardial infarction. J Am Heart Assoc. 2017;6(8):e005968.

\section{Address for Correspondence:}

Dr. Syed Muhammad Afaque, Assistant Professor of Cardiology at National Institute of Cardiovascular Diseases, Karachi, Pakistan.

Email: smafaq101@gmail.com 